\title{
Ewing's Sarcoma Family Tumors pada Anak [Keganasan Kelompok Sarkoma Ewing] di RS. Cipto Mangunkusumo
}

\author{
Teny Tjitra Sari, Djajadiman Gatot, Endang Windiastuti \\ Departemen Ilmu Kesehatan Anak Fakultas Kedokteran Universitas Indonesia RS Dr. Cipto \\ Mangunkusumo, Jakarta
}

\begin{abstract}
Latar belakang. Terapi multimodalitas pada Ewing's sarcoma family tumors (keganasan kelompok sarkoma Ewing) telah banyak meningkatkan keberhasilan terapi. Guna menilai keberhasilan terapi diperlukan data mengenai luaran pasien keganasan kelompok sarkoma Ewing.

Tujuan. Mengetahui gambaran klinis dan luaran pasien sarkoma Ewing yang dirawat di Divisi Hematologi Onkologi Departemen Ilmu Kesehatan Anak RS Cipto Mangunkusumo

Metode. Studi deskriptif dilakukan pada pasien yang didiagnosis keganasan kelompok sarkoma Ewing di Divisi Hematologi Onkologi Departemen Ilmu Kesehatan Anak RS Cipto Mangunkusumo, pada tahun 2000-2010. Terapi yang diberikan adalah kemoterapi, pembedahan, dan radioterapi.

Hasil. Selama periode pengamatan sepuluh tahun dijumpai 26 pasien keganasan kelompok sarkoma Ewing dari seluruh 2112 pasien keganasan anak. Usia berkisar 6 bulan - 13 tahun 1 bulan (median 8 tahun 3 bulan). Lokasi tersering adalah ekstremitas, tulang belakang, dan pelvis. Sebagian besar pasien (16 dari 26 pasien) datang dengan stadium lanjut. Kemoterapi terutama diberikan pada lokasi tumor aksial (12 dari 26 pasien), sedangkan pembedahan yang dilanjutkan kemoterapi dilakukan bila lokasi tumor berada di ekstremitas (4 dari 26 pasien). Pasien meninggal lebih banyak dengan lokasi tumor di aksial (9 pasien) dibanding ekstremitas ( 3 pasien). Jumlah pasien hidup lebih banyak yang berusia $<10$ tahun dibanding umur yang lebih tua ( 6 berbanding 1$)$. Residif terjadi pada dua pasien dengan jangka waktu 11 bulan.

Kesimpulan. Luaran pasien keganasan kelompok sarkoma Ewing masih jauh dari memuaskan. Pasien meninggal lebih banyak daripada pasien hidup, terutama letak tumor di aksial. Sebagian besar pasien datang pada stadium lanjut dan telah mengalami metastasis. Modalitas yang lebih intensif perlu diberikan untuk meningkatkan luaran pasien keganasan kelompok sarkoma Ewing. Sari Pediatri 2011;13(2):117-22.
\end{abstract}

Kata kunci: keganasan, sarkoma Ewing, anak

\footnotetext{
Alamat korespondensi:

Dr. Teny Tjitra Sari, Sp.A. Divisi Hematologi Onkologi Departemen Ilmu Kesehatan Anak FKUI- RSCM Jl. Salemba no. 6, Jakarta 10430. Tel.: 021-3907744, 31901170 Fax.: 021-3913982
}

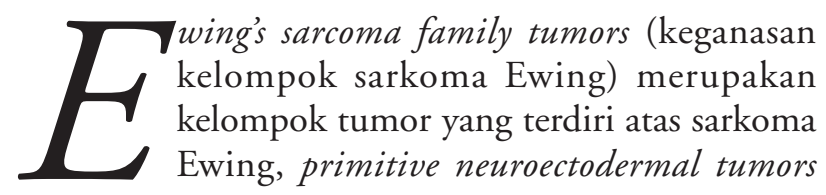


(PNET) yang terjadi di tulang dan jaringan lunak, serta tumor Askin. Pada ketiga tumor terdapat kelainan yang sama akibat adanya translokasi $\mathrm{t}(11 ; 22)(\mathrm{q} 24 ; \mathrm{q} 12)$ dan variannya sehingga terjadi fusi gen EWS-ETS yang kemudian akan berfungsi sebagai onkogen. ${ }^{1,2}$ Pada tahun 2000-2010, keganasan ini menduduki peringkat ke-13 dari seluruh keganasan pada anak di Divisi Hematologi Onkologi Departemen Ilmu Kesehatan Anak RS Cipto Mangunkusumo. ${ }^{3}$ Apabila terjadi pada tulang, tumor ini menempati peringkat kedua setelah osteosarkoma. ${ }^{3,4}$

Keberhasilan terapi pada keganasan kelompok sarkoma Ewing sudah sangat meningkat. Terapi multimodalitas telah banyak meningkatkan luaran pasien dari 15\%-20\% dengan modalitas hanya pembedahan dan/atau radiasi, menjadi 60\%-70\%. ${ }^{1}$

Tujuan penelitian ini adalah untuk mengkaji keadaan klinis dan luaran pasien sarkoma Ewing yang diterapi di Divisi Hematologi Onkologi Departemen Ilmu Kesehatan Anak RS Cipto Mangunkusumo tahun $2000-2010$.

\section{Metode}

Telah dilakukan penelitian deskriptif terhadap pasien yang didiagnosis keganasan kelompok sarkoma Ewing pada tahun 2000-2010, di Divisi Hematologi Onkologi Departemen Ilmu Kesehatan Anak RS Cipto Mangunkusumo. Kriteria inklusi penelitian adalah pasien yang didiagnosis sebagai keganasan kelompok sarkoma Ewing, termasuk peripheral neuroectodermal tumors (PNET), tumor Askin, dan usia kurang dari 18 tahun. Diagnosis dikonfirmasi dengan pemeriksaan patologi anatomi yang dapat disertai dengan gambaran imunohistokimia, termasuk CD 99. ${ }^{2}$ Pada pasien yang memiliki catatan medik tidak lengkap, tidak diikutsertakan dalam penelitian.

Data yang dikumpulkan adalah demografis (umur, jenis kelamin), lokasi tumor primer, metastasis saat diagnosis, modalitas terapi, dan luaran akhir.

\section{Hasil}

Selama sepuluh tahun observasi dijumpai 26 pasien keganasan kelompok sarkoma Ewing dari seluruh 2112 pasien keganasan anak di Divisi Hematologi
Onkologi Departemen Ilmu Kesehatan Anak RS Cipto Mangunkusumo. Usia pasien berkisar 6 bulan-13 tahun 1 bulan dengan median 8 tahun 3 bulan. Pada Tabel 1 tertera rasio anak perempuan: anak laki-laki adalah 1,3:1. Lokasi yang tersering adalah ekstremitas, tulang belakang, dan pelvis. Sebagian besar pasien (16 dari 26 pasien) datang dengan stadium lanjut (Tabel $1)$.

Modalitas terapi yang diberikan kepada pasien keganasan kelompok sarkoma Ewing adalah kemoterapi, pembedahan, dan radioterapi. Kemoterapi yang diberikan pada setiap siklusnya terdiri atas aktinomisin D $450 \mathrm{ug} / \mathrm{m} 2 /$ hari IV, adriamisin $20 \mathrm{mg} / \mathrm{m} 2 /$ hari IV, vinkristin $1,5 \mathrm{mg} / \mathrm{m} 2 \mathrm{IV}$, dan siklofosfamid 1200 $\mathrm{mg} / \mathrm{m} 2$ IV setiap 3 minggu. Sedangkan terapi lokal adalah pembedahan, radioterapi, ataupun kombinasi keduanya. Tabel 2 memperlihatkan indikasi pemberian terapi modalitas berdasarkan lokasi tumor. Modalitas kemoterapi terutama diberikan pada tumor aksial, sedangkan pembedahan dilanjutkan kemoterapi dilakukan bila tumor yang berada di ekstremitas. Terdapat 3 dari 26 pasien yang belum sempat diberikan terapi apapun, ketiganya mempunyai tumor di aksial. Hanya dua pasien yang mendapatkan kombinasi ketiga modalitas terapi yaitu satu pasien lokasi tumor di klavikula (radiasi 80 Gy) sedangkan satu pasien lokasi tumor di femur (radiasi 50 Gy). Pasien lokasi tumor klavikula akhirnya meninggal sedangkan pasien lokasi tumor di femur sampai saat ini masih menjalani kemoterapi lanjutan.

Tabel 1. Karakteristik pasien $(\mathrm{n}=26)$

\begin{tabular}{lc}
\hline Karakteristik & $\mathrm{n}$ \\
\hline Usia (tahun) & \\
$<10$ & 17 \\
$\geq 10$ & 9 \\
Jenis kelamin & \\
$\quad$ Laki-laki & 11 \\
$\quad$ Perempuan & 15 \\
Lokasi tumor primer & \\
$\quad$ Ekstremitas & 7 \\
Aksial & \\
$\quad$ Pelvis & 3 \\
$\quad$ Tulang belakang & 6 \\
$\quad$ Lainnya & 10 \\
Metastasis saat diagnosis & \\
Ya & 16 \\
Tidak & 10 \\
\hline$\quad$
\end{tabular}


Teny Tjitra Sari dkk: Ewing's sarcoma family tumors pada anak

Tabel 2. Modalitas terapi menurut lokasi tumor primer $\mathrm{n}=(23)$

\begin{tabular}{lcc}
\hline Modalitas terapi & \multicolumn{2}{c}{ Lokasi } \\
\cline { 2 - 3 } & Ekstremitas & Aksial \\
\hline Kemoterapi & 2 & 12 \\
Kemoterapi + pembedahan & 4 & 3 \\
Kemoterapi + pembedahan + radioterapi & 1 & 1 \\
\hline
\end{tabular}

Tabel 3. Luaran pasien Sarkoma Ewing menurut lokasi tumor, usia, dan metastasis

\begin{tabular}{lccccccc}
\hline \multirow{2}{*}{ Luaran } & \multirow{2}{*}{ Total } & \multicolumn{2}{c}{ Lokasi } & \multicolumn{3}{c}{ Usia } & \multicolumn{2}{c}{ Metastasis } \\
\cline { 2 - 8 } & & Ekstremitas & Aksial & $<10$ tahun & $\geq 10$ tahun & Ya & Tidak \\
\hline Hidup & 7 & 4 & 3 & 6 & 1 & 1 & 6 \\
Meninggal & 12 & 3 & 9 & 7 & 5 & 12 & 0 \\
Loss to follow up & 7 & 0 & 7 & 4 & 3 & 3 & 4 \\
\hline
\end{tabular}

Hasil luaran pasien sarkoma Ewing tertera pada Tabel 3. Pasien meninggal lebih banyak dengan lokasi tumor di aksial (9 pasien) dibanding ekstremitas (3 pasien). Jumlah pasien hidup lebih banyak yang berusia $<10$ tahun dibanding dan umur yang lebih tua (6 berbanding 1) (Tabel 3). Pasien dengan metastasis lebih banyak yang meninggal (12 berbanding 0$)$. Residif terjadi pada dua pasien dengan rentang waktu 11 bulan.

Tabel 4. Faktor prognosis keganasan kelompok sarkoma Ewing (Studi Euro-Ewing 99) ${ }^{8}$

\begin{tabular}{lc}
\hline Faktor prognosis & Skor \\
\hline Usia $>14$ tahun & 1 \\
Volume tumor $>200 \mathrm{ml}$ & 1,5 \\
1 lesi tulang & 1 \\
$>1$ lesi tulang & 1,5 \\
Metastasis sumsum tulang & 1 \\
Metastasis paru & 1 \\
\hline
\end{tabular}

\section{Pembahasan}

Selama sepuluh tahun, terdapat 26 pasien keganasan kelompok sarkoma Ewing di antara 2112 pasien keganasan anak di Divisi Hematologi Onkologi Departemen Ilmu Kesehatan Anak RS Cipto Mangunkusumo. Usia sangat penting dalam mendiagnosis keganasan kelompok sarkoma Ewing, 80\% pasien merupakan pasien anak-anak. ${ }^{2}$ Umur pasien yang didapatkan pada penelitian ini adalah 6 bulan-13 tahun 1 bulan dengan median 8 tahun 3 bulan. Anak perempuan lebih banyak dibanding anak laki-laki (rasio 1,3:1). Hal ini berbeda dengan kepustakaan yang mendapatkan keganasan kelompok sarkoma Ewing lebih sering didapatkan pada anak laki-laki. ${ }^{2,4}$ Holly dkk ${ }^{5}$ tahun 1992 menghubungkan pekerjaan ayah dengan timbulnya kejadian keganasan kelompok sarkoma Ewing. Ayah yang bekerja pada bidang agraris mempunyai risiko relatif $(R R)=8,8$, interval kepercayaan $95 \%$ 1,8;42,7) dan ayah yang berhubungan erat dengan pestisida mempunyai risiko relatif $(\mathrm{RR}=6,1$, interval kepercayaan $95 \% 1,7 ; 21,9) .^{5}$

Tempat predileksi terjadinya keganasan kelompok Sarkoma Ewing adalah batang tubuh dan tulang panjang, (lebih sering terjadi di tulang femur). Berbeda dengan osteosarkoma, tumor timbul di daerah diafisis bukan di metafisis. Metastasis lebih sering ke paru dan tulang lainnya dengan tempat predileksi adalah rongga torak, otot paravertebra, ekstremitas, gluteus dan ruang retroperitoneal. ${ }^{2}$ Lokasi tersering yang terkena didapatkan adalah ekstremitas, diikuti tulang belakang, dan pelvis.

Terapi keganasan kelompok sarkoma Ewing termasuk kemoterapi untuk mengatasi metastasis jauh tanpa melihat stadium. Sebelum penggunaan kemoterapi, angka kesintasan jangka panjang adalah kurang dari $10 \%$. Namun, saat ini dengan adanya kemoterapi intensif, beberapa senter telah melaporkan angka kesintasan 5 tahun telah mencapai hingga $80 \%$ yang memperlihatkan bahwa keganasan kelompok sarkoma Ewing sangat sensitif terhadap kemoterapi. ${ }^{1,6}$ Angka kesintasan yang sangat meningkat disebabkan adanya kemajuan 
pada terapi lokal tumor, yaitu terapi radioterapi yang lebih maju dan pembedahan yang lebih agresif.? Pada umumnya, kemoterapi yang digunakan terdiri dari doksorubisin, siklofosfamid, vinkristin, aktinomisin-D, ifosfamid, dan etoposid. ${ }^{2}$ Terapi yang diberikan di Divisi Hematologi Onkologi Departemen Ilmu Kesehatan Anak RS Cipto Mangunkusumo terdiri dari aktinomisin-D, adriamisin, vinkristin, dan siklofosfamid. Pemberian siklofosfamid tampaknya mempunyai angka kesintasan 5 tahun yang sama dengan pemberian ifosfamid pada pasien risiko standar ( $82 \%$ versus $84 \%$, hazard ratio 1,08 , interval kepercayaan $95 \%$ $0,58 ; 2,03) .{ }^{6}$ Granowetter $\mathrm{dkk}^{1}$ membandingkan pemberian kemoterapi regimen standar dengan regimen intensif pada keganasan kelompok sarkoma Ewing tanpa metastasis. Regimen standar diberikan 17 siklus selama 48 minggu sedangkan regimen intensif diberikan 11 siklus selama 30 minggu tetapi jumlah total dosis kemoterapi tetap sama antara regimen standar dan regimen intensif. Hasil pengobatan menunjukkan tidak ada perbedaan angka kesintasan 5 tahun antara pasien yang diterapi regimen standar (72,1\%; interval kepercayaan $95 \%$ $65,8 \% ; 77,5 \%)$ dengan regimen intensif $(70,1 \%$; interval kepercayaan 95\% 63,9\%;75\%). Selain itu tidak ada perbedaan luaran pasien keganasan kelompok sarkoma Ewing dengan tumor primer di tulang dan jaringan lunak. ${ }^{1}$

Pada pasien risiko tinggi yaitu yang disertai dengan metastasis, pemberian etoposid tampaknya sangat bermanfaat yang ditunjukkan dengan penurunan risiko kematian $17 \%$ dan peningkatan angka kesintasan 3 tahun (59\% vs $62 \%$, hazard ratio 0,85 , interval kepercayaan 95\% 0,66;1,10). ${ }^{6}$ Ladenstein $\mathrm{dkk}^{8}$ dalam studi Euro-Ewing 1999 memberikan kemoterapi dosis tinggi disertai pemberian busulfanmelphalan dosis tinggi diikuti transplantasi sumsum tulang. Ternyata hasil pengobatan tetap tidak lebih baik, yaitu angka kesintasan 3 tahun hanyalah $34 \% \pm 4 \%{ }^{8}$

Salah satu yang penting diperhatikan pada terapi keganasan kelompok sarkoma Ewing adalah terapi lokal. Laporan terdahulu menunjukkan penurunan rekurensi lokal dan peningkatan angka kesintasan dengan melakukan reseksi luas tumor primer. Terapi lokal lebih diutamakan dengan pembedahan sedapat mungkin. Pemilihan pembedahan dan radioterapi harus dipilih secara individual. Bila pencitraan sebelum operasi memperlihatkan pembedahan mampu mereseksi seluas mungkin, maka dipilih terapi reseksi tanpa radiasi. Bila tepi sayatan tidak memungkinkan bebas tumor, maka harus ditambahkan radioterapi pre-operasi. Bila lesi sentral, besar, tidak dapat direseksi, maka terkadang hanya diberikan radioterapi pada tumor primer. Studi European intergroup cooperative Ewings sarcoma study (EICESS) memperlihatkan bahwa terapi pembedahan dan radioterapi mempunyai hasil yang sama dengan hasil radioterapi saja. ${ }^{2}$ Terapi lokal pada umumnya dilakukan setelah minggu ke-12 dan terdiri atas reseksi tumor atau radioterapi. Bila tepi sayatan terlalu dekat atau positif mengandung tumor, maka akan diberikan radioterapi setelah reseksi. Bila pasien hanya mendapat radiasi pada minggu ke-12, maka reseksi akan dilakukan pada minggu ke-30. Radioterapi diberikan sebanyak 50,4-55,8 Gy. Radiasi tidak diberikan pada pasien yang telah direseksi secara komplet sebelumnya. ${ }^{1}$ Di Divisi Hematologi Onkologi Departemen Ilmu Kesehatan Anak RS Cipto Mangunkusumo, radiasi diberikan dengan dosis 50 Gy dan 80 Gy. Pada pasien keganasan kelompok sarkoma Ewing di pelvis, tidak ada perbedaan hasil terapi lokal antara pembedahan, radioterapi, dan kombinasi pembedahan-radioterapi. Hal ini dikarenakan penentuan terapi lokal sangat tergantung penilaian klinis sehingga tidak banyak mempengaruhi angka kesintasan. ${ }^{9}$ Kegagalan terapi lokal dihubungkan dengan besar tumor dan tipe terapi lokal. Pasien tanpa metastasis, tumor lebih kecil $(<8 \mathrm{~cm})$ dan adanya terapi lokal pembedahan dengan atau tanpa radiasi mempunyai keberhasilan terapi yang lebih tinggi. ${ }^{7}$

Salah satu faktor prognosis buruk pada pasien keganasan kelompok sarkoma Ewing adalah metastasis jauh. Dengan adanya metastasis, angka kesintasan hanya 20\%-30\% walau dengan terapi agresif. ${ }^{2,8}$ Pasien dengan metastasis tulang atau sumsum tulang mempunyai prognosis yang lebih buruk dibanding metastasis paru (kurang dari 20\% versus 30\%). Faktor prognosis buruk lainnya adalah usia $>10$ tahun, tumor $>200 \mathrm{ml}$, lesi di daerah aksial (pelvis atau tulang belakang) dan respons buruk terhadap kemoterapi. ${ }^{2,10}$ Didapatkan pasien yang meninggal lebih banyak berusia $<10$ tahun dan sebagian besar sudah mengalami metastasis (64\%) sehingga prognosis menjadi buruk. Selain itu, tampak bahwa pasien meninggal lebih banyak 
pada lokasi tumor aksial yang merupakan salah satu prognosis buruk. Argon $\mathrm{dkk}^{10}$ mendapatkan prognosis buruk paling kuat terlihat bila tumor berada di pelvis (RR 7,5; interval kepercayaan 95\% $1,52 ; 37,06] .{ }^{10}$

Studi Euro-Ewing tahun 1999 mendapatkan prognosis makin buruk bila tumor $>200 \mathrm{ml}$ (HR 1,8, interval kepercayaan 95\%, 1,3 sampai 2,5), lebih dari 1 metastasis tulang ( $\mathrm{HR}=2,0$ interval kepercayaan $95 \%, 1,2$ sampai 3,3$)$, metastasis sumsum tulang ( $\mathrm{HR}=1,6$ interval kepercayaan 95\%, 1,2 sampai 2,2) dan metastasis paru $(\mathrm{HR}=1,5$ konfidens interval 95\%, 1,2 sampai 2,1). Keseluruhan faktor prognosis ini dibuat dalam skor dan tertera pada Tabel 4. Bila jumlah skor $\leq 3$, maka event free survival 3 tahun adalah 50\%. Bila jumlah skor $>3-<5$, maka event free survival 3 tahun adalah $25 \%$. Bila jumlah skor $\geq 5$, maka Event Free Survival 3 tahun adalah 10\%. ${ }^{8}$

Ekspresi MGST1 (microsomal glutathione S-transferase-1) dapat memprediksi prognosis sarkoma Ewing. Ekspresi ini berhubungan dengan sensitifitas terhadap doxorubisin. Hal tersebut dihubungkan dengan efektifitas 6-(7-nitro-2,1,3-benzoxadiazol-4ylthio)hexanol (NBDHEX) sebuah agen antikanker baru yang dapat menghambat enzim GST (Glutation S-transferase). ${ }^{11}$

Tampaknya pengobatan keganasan kelompok Sarkoma Ewing masih jauh dari memuaskan. Bacci $\mathrm{dkk}^{12}$ mendapatkan 25 pasien residif dalam waktu 5,5 sampai 15 tahun (rerata 7,7 tahun), 7 pasien menderita sarkoma akibat radiasi dalam waktu 6 sampai 20 tahun (rerata 9,3 tahun) dan 2 pasien menderita tumor padat sekunder dalam waktu 20 - 23 tahun kemudian. Di Divisi Hematologi Onkologi Departemen Ilmu Kesehatan Anak RS Cipto Mangunkusumo terdapat 2 pasien yang residif dalam jangka waktu 11 bulan, sedangkan Rodr guez-Galindo $\mathrm{dkk}^{7}$ mendapatkan 95 pasien residif dalam jangka waktu 1,6 tahun. Hal ini mungkin karena perbedaan modalitas terapi yang diberikan.

Sebagai kesimpulan, luaran pasien keganasan kelompok sarkoma Ewing yang diterapi di Divisi Hematologi Onkologi Departemen Ilmu Kesehatan Anak RS Cipto Mangunkusumo masih jauh dari memuaskan. Pasien meninggal lebih banyak daripada pasien hidup, dan ini terutama dengan letak tumor di aksial. Selain itu, sebagian besar pasien juga datang dengan keadaan stadium lanjut yaitu sudah terdapat metastasis. Modalitas terapi yang lebih intensif perlu diberikan untuk meningkatkan luaran pasien keganasan kelompok sarkoma Ewing.

\section{Daftar pustaka}

1. Granowetter L, Womer R, Devidas M, Krailo M, Wang C, Bernstein M, dkk. Dose-intesified compared with standard chemotherapy for nonmetastatic Ewing sarcoma family of tumors: A Children's Oncology Group Study. J Clin Oncol 2009;27:2536-41.

2. Iwamoto Y. Diagnosis and treatment of Ewing's Sarcoma. Jpn J Clin Oncol 2007;37:79-89.

3. Data Registrasi Kanker Divisi Hematologi Onkologi IKA FKUI/RSCM tahun 2000 - 2010.

4. Levy CF. Malignant bone tumors. Dalam: Lanzkowsky P, penyunting. Manual of pediatric hematology and oncology. Edisi ke-5. Oxford: Elsevier Inc; 2011. h. 749-57.

5. Holly EA, Aston DA, Ann DK, Kristiansen JJ. Ewing's bone sarcoma, paternal occupational exposure and other factors. Am J Epidemiol 1992;135:122-9.

6. Paulussen M, Craft AW, Lewis I, Hackshaw A. Douglas C, Dunst J, dkk. Results of the EICESS-92 study: Two randomized trials of Ewing's sarcoma treatmentCylophosphamide compared with ifosfamide in standard-risk patients and assessment of benefit of etoposide added to standard treatment in high-righ patients. J Clin Oncol 2008;26:4385-93.

7. Rodriguez-Galindo C, Navid F, Liu T, Billups CA, Rao BN, Krasin MJ. Prognostic factors for local and distant control in Ewing sarcoma family of tumors. Ann Oncol 2008;19:814-20.

8. Ladenstein R, Pötschger U, Le Deley MC, Whelan J, Paulussen M, Oberlin O dkk. Primary disseminated multifocal Ewing sarcoma: results of the Euro-Ewing 99 trial. J Clin Oncol 2010;28:3284-91.

9. Yock TI, Krailo M, Fryer CJ, Donalson SS, Miser JS, Chen Z, dkk. Local control in pelvic Ewing Sarcoma: analysis from INT-0091-A report from the Children's Oncology Group. J Clin Oncol 2006;24:3838-43.

10. Argon A, Basaran M, Yaman F, Dizdar Y, Sakar B, Camlica H, dkk. Ewing's sarcoma of the axial system in patients older than 15 years: dismal prognosis despite intensive multiagent chemotherapy and aggressive local treatment. Jpn J Clin Oncol 2004;34:667-72.

11. Scotlandi K, Remondini D, Castellani G, Manara MC, Nardi F, Cantiani L, dkk. Overcoming resistance to conventional drugs in Ewing sarcoma and identification 
Teny Tjitra Sari dkk: Ewing's sarcoma family tumors pada anak

of molecular predictors of outcome. J Clin Oncol 2009;27:2209-16.

12. Bacci G, Balladelli A, Forni C, Ferrari S, Longhi A, Benassi MS, dkk. Adjuvant and neo-adjuvant chemotherapy for
Ewing's sarcoma family tumors and osteosarcoma of the extremity: further outcome for patients event-free survivors 5 years from the beginning of treatment. Ann Oncol 2007;18:2037-40. 